colour tests as Millon's, nitric acid, \&c., have no real value; the colour developed may be due to the proteid molecule as a whole, but more probably to some decomposition product, and, as already mentioned, some colloids which bear no relation to actual proteids give reactions considered characteristic of these substances. Again, the peptons in their reactions strangely recall the alkaloids, especially in the precipitates they give with mercuric chloride, potassium periodide, phosphotungstic and phosphomolybdic acids, \&c., while elementary analysis is of little value, as all the proteids give very similar figures, which in nowise indicate the striking differences met with in their physiological behaviour. When, in addition, it is remembered how extremely complex and mobile the proteid molecule must of necessity be, and the readiness with which changes in its constitution are brought about, something more than a few empirical colour and physiological tests will be required to convince chemists that pepton has been actually synthesised. Dr. Lilienfeld's results evidently need further investigation, and in the meantime the question raised by his announcement is distinctly one that calls for suspended judgment.

SIDNEY WIILLIAMSON.

\section{THE TOXICITY OF EEL-SERUM, AND} FURTHER STUDIES ON IMMUNITY.

$T \mathrm{HE}$ investigation of poisons, both bacterial and animal, has been pursued with such enthusiasm in so many parts of the world during the past decade, and the public have been brought into such close touch with some of the practical applications which have followed in the track of these investigations, that the term toxin and anti-toxin, unknown in the days of Dr. Johnson's colossal dictionary, may now without exaggeration be said to form part of the vocabulary of every well-ordered household.

But whilst the more striking beneficent results obtained in the study of immunity have become public property, so to speak, a mass of important and most interesting researches remain concealed from the layman's view, locked away, as far as he is concerned, in the pages of divers scientific journals.

Of such researches we may cite those which have relegated the blood-serum of eels to the category of poisons. This remarkable discovery was made as long ago as the year I 888 by A. Mosso, ${ }^{1}$ of Turin, who found that the serum of eels, when subcutaneously and intravenously inoculated into animals produced fatal results, although it was quite harmless when introduced per os. Half a cubic centimetre of eel-serum inoculated into a dog weighing I4 lbs. killed the animal in seven minutes ; and Mosso obtained similarly lethal results in the case of rabbits, guinea-pigs, frogs, and pigeons.

But little further attention appears to have been paid to this subject until Calmette, ${ }^{2}$ in 1895 , and Phisalix, ${ }^{3}$ in 1896, carried out further experiments on the toxic character of such serum from an immunising point of view, and this year we have had quite a crop of memoirs on eel-serum treated from various sides, and our information is consequently greatly extended concerning both the character of this poison and its antidote.

It appears that the toxic effect of this eel-serum varies according to the manner in which it is introduced into an animal, and the different quantities required to produce lethal subcutaneous, intravenous, and intraperitoneal inoculations respectively have been elaborately determined by Maglieri, ${ }^{4}$ who states that for every $2-1 \mathrm{~b}$. weight of

1 Archives Italiennes de Biologie, vol. x., 1888 ;

2 "Venins, toxines et sérums antitoxiques" (Annales de l'Institut Pasteur, vol. ix., 1895).

3 Comptes rendus de $l$ Académie des sciences, 1896.

4 "Sull'azione tossica immunizzante e battericida del siero di sangue di anguilla." (Annali d'Igiene Sperimentale, 1897.)

NO. I 503 , VOL. 58 ] rabbit employed from $\mathrm{O} 2$ to 025 c.c. of serum is required in intravenous inoculations, 4 to 45 c.c. in subcutaneous inoculations, and 20 to 25 c.c. in intraperitoneal inoculations. Héricourt and Richet ${ }^{1}$ mention that in their experiments ${ }^{\prime}$ c c.c. intravenously introduced was fixed as the lethal dose of serum for a rabbit weighing 4 lbs.

Wehrmann, ${ }^{2}$ however, remarks that it is in reality very difficult to lay down a general law as to the exact quantity of this serum which will constitute a fatal dose, for it not only varies in toxic strength at different times of the year, but in eels of different origin; and it is, therefore, necessary to determine the toxic value of such serum each time a fresh supply is collected.

Before passing on to the experiments which have been carried out on modifying the lethal activity of this eel-serum, and on artificially protecting animals from its toxic action, we may refer to some interesting investigations made by Maglieri (loc. cit.) to ascertain whether such serum is endowed with any bactericidal properties. For this purpose tubes containing eel-serum were inoculated with colon bacilli ( $B$. coli communis), cholera vibrios, and dipththeria bacilli respectively; after different intervals of time, varying from fifteen minutes up to twenty-four hours, gelatine and broth tubes were inoculated from all the serum-tubes. In every case a positive result was obtained; that is to say, growths of the three different microbes employed subsequently appeared in all the gelatine and broth tubes, indicating that, however lethal this eel-serum may be in regard to animal life, these minute vegetables - or, at any rate, the three varieties above mentioned-enjoy a natural immunity from its toxic action.

The quantity of blood which is procurable from even a large eel weighing about $5 \mathrm{lbs}$. is very small, never more than 25 cubic centimetres, and this only yields from Io to 12 c.c. of serum, whilst in the case of vipers a relatively large quantity of blood is obtained. This eelserum, according to Wehrmann, can be kept in a fit experimental condition for two weeks if stored over ice and in the dark, but Maglieri states that its toxicity declines gradually after the eighth day of its collection even when protected from light.

As regards the artificial modification of the lethal properties of eel-serum, U. Mosso, ${ }^{3}$ a brother of the Mosso already referred to, mentions, amongst other devices, that heating the serum to from $68^{\circ}$ to $78^{\circ} \mathrm{C}$. removed its toxic character. Phisalix (loc. cit.) also found that heating it to $58^{\circ} \mathrm{C}$. for a quarter of an hour destroyed its toxicity, and that such heated serum was capable of endowing animals with immunity towards ordinary eel-serum, this immunity being, however, of a very transitory character. Wehrmann found that exposing it to this temperature for a quarter of an hour removed the greater portion of its toxic powers, and when animals were inoculated with serum thus treated, a somnolent state, sometimes accompanied by a depression of temperature, followed, but that they recovered their normal condition at the end of from two to three hours, having meanwhile acquired a certain degree of immunity from the effect of ordinary eel-serum inoculations, which was retained for three days. Maglieri found that preserving eel-serum at a constant temperature of only $37^{\circ}$ C. for the space of twenty-four hours was sufficient to greatly modify its toxicity. Very interesting is the ob. servation recorded by Wehrmann that by subcutaneously inoculating anti-venomous serum ${ }^{4}$ into eels the toxicity of their blood is considerably reduced. Thus an eel weighing about half a pound was inoculated with 5 cubic

1 Comptes rendus de la Société de Biologie, I897.

2 "Recherches sur les propriétés toxiques et antitoxiques du sang et de la bile des Anguilles et des Vipères" (Annales de l'Institut Pasteur, p. 8ro, 189.)

3 Archives Italiennes de Biologie, 1889

4 Serum derived from an animal rendered artificially immune to the poisonous action of snake-venom. 
centimetres of anti-venomous serum, after twenty-four hours it was killed, and instead of 2 c.c. of serum sufficing to kill as usual a guinea-pig, 4 c.c. of this particular eel's serum was required.

In this connection we may quote an observation of Calmette's, ${ }^{1}$ made in the course of his classical experiments on the toxic character of the blood of venomous serpents, that the toxicity of the blood of such reptiles may be entirely removed by inoculating them with antivenomous serum. Thus a large specimen of the naja tripudians received a series of anti-venomous serum inoculations, and two weeks after the last inoculation it was killed, and its blood was found to have lost all its toxic character, ${ }^{2}$. whilst that of another untreated naja tripudians exhibited its customary complement of lethal qualities.

It would be interesting to determine in the case of eels and vipers the relative quantity of anti-venomous serum which is required to remove the toxicity of their blood respectively, for, curiously, the blood of eels is three times more toxic than that of vipers; and whilst the blood of eels acts as a preventive, protecting an animal from the lethal action of vipers' blood, the latter has no corresponding power to protect an animal from the fatal effect of eels' blood.

Of great interest are the numerous investigations which have been carried out by Wehrmann to ascertain the action of various other serums as well as biles of different origin upon this eel-serum. Anti-venomous serum, it appears, acts as an antitoxin towards eelserum, for it not only protects animals from a subsequent otherwise fatal dose of eel-serum, but if administered even after the eel-serum has been introduced into the animal, it nullifies its effect, and the animal lives, whilst it also neutralises the action of eel-serum outside the animal's body in vitro. Different varieties of serum did not, however, all operate as successfully as antivenomous serum. For example, anti-tetanic serum produced no effect upon the toxicity of eel-serum; neither did the normal serums of horses and rabbits. Antidiphtheritic serum, on the other hand, acted as a preventive, and also neutralised the toxicity of eel-serum in vitro, but was not endowed with any curative power in respect to its toxic action.

Wehrmann has next studied the effect produced by bile derived from eels, from oxen, and from vipers, not only on the toxicity of eel-serum, but also on that of viper-serum and viper-venom. Now Fraser (British Medical Journal, July I897) has recently asserted that the bile of serpents and other animals is antitoxic as regards serpent-venom, that it not only has a neutralising action in vitro, but that it has also a distinct, although feebly marked, curative power in respect to this venom. Fraser mentions the interesting fact, in support of his observations, that in some countries the natives have a practice of administering the bile of a serpent to people who have been very badly bitten by poisonous snakes.

According to Wehrmann, viper-bile has a preventive as well as neutralising action with respect to vipervenom ; but he does not say that he has found it to possess, as Fraser has done, a curative power. This viper-bile has also a preventive and neutralising action as regards the toxic properties of viper-serum and eel-serum.

Ox-bile, on the other hand, was found to possess no antitoxic action in the doses employed by Wehrmann on viper-venom, neither was it endowed with any preventive or curative powers in respect to eel-serum.

Eel-bile, again, was devoid of all preventive or curative powers in regard to eel-serum and to viper-venom.

1 " Contributions a l'étude des venins des toxines et des serums anticoxiques." (Annales de l'Institut Pasteur, vol. ix., 189.5.)

The toxic properties of the venom of this naja tripudians were not in any way affected, indicating, as Calmette points out, that the lethal prin. ciple of which the venom consists is not elaborated in the blood, but in the cells of the venom glands of poisonous reptiles.

$$
\text { NO. I } 503 \text {, VOL. } 58]
$$

It was able to neutralise the toxicity of both these toxins in vitro, and had a greater degree of neutralising power in respect to the venom than to the eel-serum. Thus, according to Wehrmann, the biles he has employed are not endowed with strictly antitoxic powers, as was claimed for serpent-bile by Fraser, but act apparently as a digestive more than anything else upon the serums and venoms with which they are mixed.

We now come to the experiments which have been carried out on the artificial production of immunity in animals from the toxic action of eel-serum.

Although heated eel-serum can afford protection to animals, yet immunity thus acquired, as we have already seen, is of so temporary a character that this method is not, as a rule, employed. The plan usually adopted by investigators consists in inoculating increasingly large doses, either intraperitoneally or intravenously, of ordinary eel-serum into the animal it is desired to render immune. By this means Maglieri and Wehrmann have both succeeded in immunising rabbits against the effects of ten, twelve, up to twenty (Maglieri) otherwise fatal doses of toxic eel-serum. The period over which the treatment has to be extended is somewhat lengthy before the requisite stage of immunity is reached. Thus, about three months must elapse before a rabbit's serum has acquired the degree of protective power to render it of use for experimental purposes. Héricourt and Richet have succeeded also in immunising a dog against eelserum, and have obtained a protective serum from this animal.

According to Wehrmann, the serum of a rabbit immunised against eel-serum acts both as a preventive and curative with regard to the serum of vipers, and to the serum of eels, as well as to the venom of vipers. This observation supports the opinion frequently expressed by Calmette in his memoirs, that the idea of the specific character of toxins and their antitoxins is not justified by experiment; that, on the contrary, the serums of animals immunised against one poison may be, and frequently are, curative as regards other poisons.

It will be remembered, however, that Calmette's assertion, that the serum of an animal which had attained a high degree of immunity against cobra venom was equally valuable as a remedy against the poison of all snakes, has not been supported by other observers; for as regards the venom of the Indian daboia, for example, Cunningham, ${ }^{1}$ of Calcutta, has found that Calmette's serum is inoperative, and therefore useless.

C. J. Martin, of Melbourne, ${ }^{2}$ has still more recently tested Calmette's serum for antidotal action in the case of the venom of the tiger snake (Hoplocephalus curtus) and the venom of the black snake (Pseudechis porphyriacus), and in the matter of both these venoms he obtained no antidotal action with Calmette's serum.

Some interesting experiments were also made by Martin to ascertain if Calmette's serum possessed antidotal action in respect to one of the two proteid con. stituents to which, according to Mitchell and Reichert, ${ }^{3}$ the venoms of snakes are supposed to owe their poisonous properties. Apparently, if the serum is introduced under the most advantageous circumstances, i.e. injected in considerable quantities directly into the circulation before the poison (in this case one of the proteids separated out from the venom of the Australian tiger snake is inoculated), the serum exhibits decided protective properties; but the immunity thus produced is so slight, that Martin is of opinion that it is practically valueless as a remedial agent, even against one only of the poisonous

1 "Scientific Memoirs, by Medical Officers of the Army of India," vol. ix., 1895

2 "The Curative Value of Calmette's Anti-Venomous Serum in the Treat ment of Inoculations with the Poisons of Australian Snakes" (Intercolonial Medical Journal of Australasia, August 1897).

3 "Researches upon the Venoms of Poisonous Serpents" ("Smithsonian Contribution to Knowledge," vol. xxvi., 1886). 
constituents of this venom. It is only just to Calmette to add that Martin's criticism, of course, only applies to the serum as he was able to obtain it as imported into Australia ; and Martin himself is careful to add that the specimens he had access to were only possessed of very feeble powers.

Wehrmann's valuable memoir, to which we so frequently have referred in the foregoing brief résumé of some of the latest contributions to the everincreasing domain of preventive medicine, is a record of experiments carried out under the inspiration of Calmette in the Institut Pasteur at Lille. It is full of experimental data, and no attempt is made to formulate theories on the facts recorded, only at the close the following suggestion is to be found :- "Enfin nous voyons que les sérums des animaux immunisés contre l'un quelconque des poisons que nous avous étudiés sout fréquemment curatifs à l'égard des autres.

"Ces phénomènes d'action réciproque préventive, neutralisante in vitro et curative, apportent un argument de plus en faveur de la théorie cellulaire de l'immunité. .. . Il faut bien en conclure que la notion de spécificité des toxines et des sérums antitoxiques est loin d'être aussi étroite qu'on l'avait cru jusqu'à ces derniers temps."

G. C. FranKLAND.

\section{THE RECENT PERSEID METEORIC SHOWER.}

THIS display appears to have been of rather a special character on August II, and to have attracted a considerable amount of attention. At any rate, during the thirty years in which I have witnessed returns of the shower, I have never known it to have been so generally observed. Many people, quite unaware that such a phenomenon was in progress, on looking up and admiring the singular beauty of the night, noticed the meteors. They were so numerous and occasionally so brilliant that they were watched for a considerable time.

Usually the maximum of the shower occurs on August ro, but on that date the atmosphere was, on the whole, unfavourable this year, and at the majority of stations not many Perseids appear to have been observed. The following evening came in under vastly improved conditions, the stars shone with remarkable lucidity, and it was quite an ideal night for the observation of meteors. To this circumstance, and to the fact that the shower was really a strong one, perhaps coming a little later than usual, is to be ascribed its marked prominence.

In the twilight at $8 \mathrm{~h} .58 \mathrm{~m}$. a splendid meteor brighter than Jupiter was seen in the S.S.W. sky, moving very slowly and almost horizontally westwards amongst the stars of Ophiuchus and Serpens. It threw off a thick train of yellow sparks, but, when near $\epsilon$ Serpentis, the nucleus, after a sudden accession of brilliancy, collapsed, and I thought the whole thing had vanished until, in the same direction of motion, a star-like fragment became visible and travelled some $8^{\circ}$ further. It moved very much slower than the earlier and brighter part of the meteor had done, and looked like a mere spark sailing along on the wind. This meteor was also observed at Slough and other places, and it will be possible to obtain some interesting deductions respecting it. It was manifestly not a Perseid; its leisurely flight being directed from the region of Pisces and Aquarius.

At Io p.m. I began watching the eastern sky, and immediately found that the Perseids, with their swift motions and phosphorescent streaks, were in strong evidence. During the $4 \frac{1}{2}$ hours ending 2.30 a.m. on August I2 I saw 106 of them, but I believe that a continuous watch of the sky would have enabled twice this number to have been counted. Whenever bright meteors appeared, or others were observed with great exactness, they were carefully registered ; and during these intervals, when attention was distracted from the sky, many Perseids must have escaped my notice. I think that one observer might have counted quite 50 meteors per hour in an uninterrupted view of the sky or the night of August II.

I endeavoured to ascertain the position of the radiant point as precisely as possible, and obtained it at hourly intervals from the best observed paths in the region immediately surrounding it. The results were as follow:-

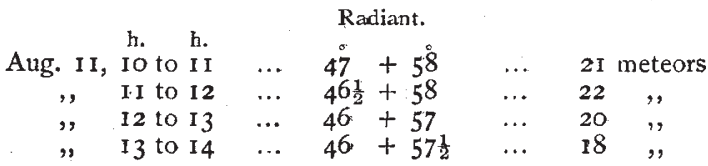

The mean is at $46^{\circ} \cdot 4+57^{\circ} 6$, which I believe is well within $r^{\circ}$ of probable error. The centre was defined with tolerable sharpness, for all the registered paths intersect within an area of about $4^{\circ}$ diameter.

Some conspicuous meteors were observed during the night, though no really large fireballs appeared. It may be advisable to give the apparent courses of the brighter objects, for some of them must certainly have been seen by other observers, many of whom were watching the sky on the same night.

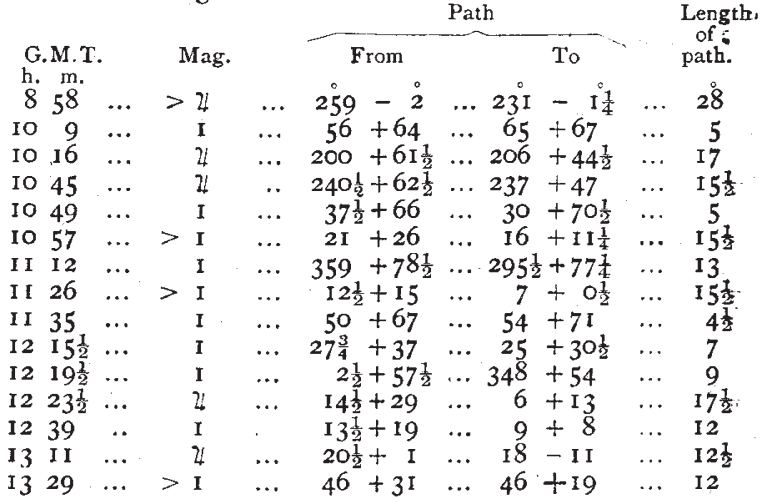

With the exception of the first, all these were Perseids.

It is satisfactory to note that reports from other quarters show that the display was very successfully observed. Prof. Herschel, at Slough, describes the rate of appearance and general brightness of the meteors on the night of August I I as considerably greater than on other dates, and mentions having mapped 80 observed paths between $\mathrm{IO}_{2} \mathrm{~h}$. and $\mathrm{I} 4 \mathrm{~h}$. Four of the Perseids observed at Bristol were also recorded by him at Slough, and he finds their radiants very definitely and distinctly marked at about. $46^{\circ}+58^{\circ}$

At Paris, it appears that very favourable conditions prevailed on August ro, so that Mlle. Klumpe, at the Observatory, succeeded in observing 200 shooting stars. The display is stated to have begun at sunset and to have continued with "amazing rapidity" until sunrise. It is estimated that altogether at least 600 shooting stars were noticed. W. F. DENNING.

\section{NOTES.}

THE proposal made at the Toronto meeting of the British Association last year, for a marine biological station in the Dominion of Canada, is taking practical shape. Such a proposal has been in the minds of Canadian biologists for many years, and Prof. Prince, the Dominion Commissioner of Fisheries, reported at length upon the necessity for such a marine station for Canada in the Marine and Fisheries Blue Book, I894, and the Royal Society of Canada also urged the

$$
\text { NO. I 5O3, VOL. 58] }
$$

